\title{
Erratum to: Biochemical, genetic, and metabolic engineering strategies to enhance coproduction of 1-propanol and ethanol in engineered Escherichia coli
}

Kajan Srirangan • Xuejia Liu • Adam Westbrook • Lamees Akawi • Michael E. Pyne • Murray Moo-Young • C. Perry Chou

Published online: 31 October 2014

(C) Springer-Verlag Berlin Heidelberg 2014

Erratum to: Appl Microbiol Biotechnol (2014)

DOI 10.1007/s00253-014-6093-9

The original version of this article contains an error.

Figure $1 \mathrm{~b}$ was incorrectly presented. See below corrected Fig. 1b.

The online version of the original article can be found at http:// dx.doi.org/10.1007/s00253-014-6093-9.

K. Srirangan · X. Liu · A. Westbrook · L. Akawi · M. E. Pyne · M. Moo-Young $\cdot$ C. P. Chou $(\bowtie)$

Department of Chemical Engineering, University of Waterloo, 200 University Avenue West, Waterloo, Ontario, Canada N2L 3G1

e-mail: cpchou@uwaterloo.ca 


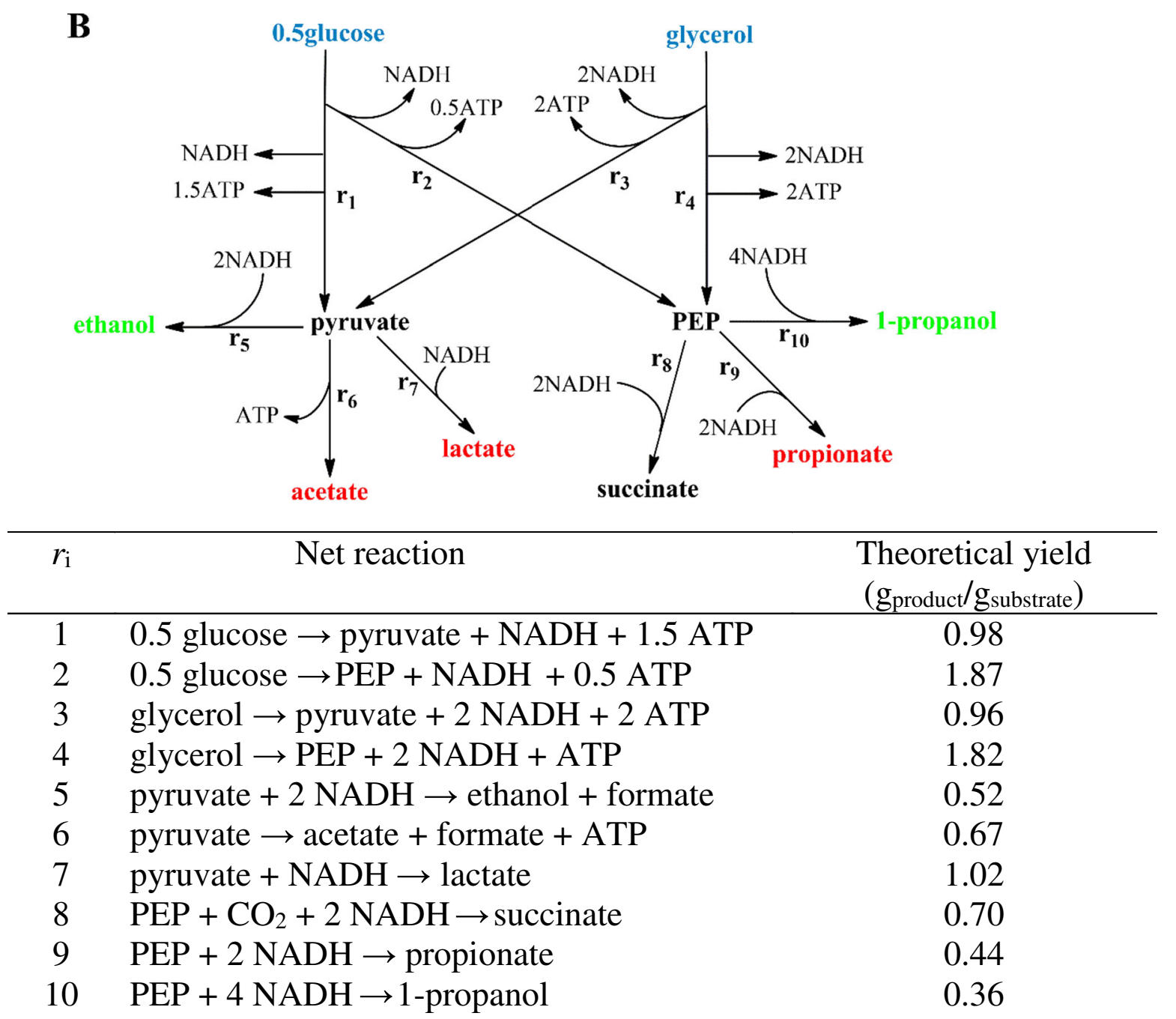

